\title{
Comparison of heat transfer coefficients of open micro- channels and plain micro-fins
}

\author{
Robert Kaniowski ${ }^{1}$, Robert Pastuszko ${ }^{1, *}$ \\ ${ }^{1}$ Kielce University of Technology, Chair of Mechanics, al. 1000-lecia Państwa Polskiego 7, PL-25-314 Kielce, Poland
}

\begin{abstract}
The paper describes results of analysis of pool boiling heat transfer on enhanced surfaces. Two types of structural surfaces were used: open microchannel surfaces consisting of a system of parallel microchannels $0.3 \mathrm{~mm}$ wide, from 0.2 to $0.5 \mathrm{~mm}$ deep and with a pitch of $0.6 \mathrm{~mm}$, and plain micro-fins $0.5 \mathrm{~mm}$ in height, uniformly spaced on the base surface with a spacing from 0.6 to1.5 mm. Pool boiling data at atmospheric pressure were obtained for saturated water, ethanol and FC-72. The effects of microchannel/micro-fin dimensions on heat transfer coefficient in nucleate pool boiling were examined. Substantial enhancement of heat transfer coefficient was observed.
\end{abstract}

\section{Introduction}

Miniaturization and significant increase in the power of electronic chips requires mastering cooling techniques. High heat fluxes are typically generated by compact heat exchangers, heat pipes, nuclear reactors, internal combustion engines, and gas turbines.

Passive cooling techniques such as like fins, microchannels, etc. are widely used for boiling heat transfer enhancement for their compatibility and potential for cooling miniaturized devices [1]. Manufacture of surfaces with micro-fins and micro-channels is relatively simple and does not generate excessive costs.

Passive methods encompass a number of enhancement techniques. Surfaces with plain micro-fins and open micro-channels fall into three categories:

- Surfaces with uniformly spaced micro-fins. Rainey and You [2] used surfaces with 0 to $8 \mathrm{~mm}$ long fins. Heat transfer enhancement was significant only for the fins with maximum length of $5 \mathrm{~mm}$. Pastuszko [3] used surfaces with plain micro-fins for boiling of FC-72. Heat transfer coefficients were higher than from micro-fins with a wire mesh. $\mathrm{Yu}$ and $\mathrm{Lu}$ [4] applied a system of $1 \mathrm{~mm}$ thick micro-fins with heights from 0.5 to $4 \mathrm{~mm}$ for FC-72. Chan et al. [5] used finned surfaces for boiling water at near vacuum pressures and fins $0.75-15 \mathrm{~mm}$ high and $0.5-2 \mathrm{~mm}$ wide. Honda et al. [6], Wei and Honda [7] and Wei et al. [8] investigated pool boiling of FC-72 on micro-fins ( $0.05 \mathrm{~mm}$ thick and up to 0.270 $\mathrm{mm}$ high) formed by dry etching directly on silicon semiconductor wafers.

- Surfaces with micro-fins spaced uniformly or nonuniformly. Gugliemini et al. [9] used 3 or $6 \mathrm{~mm}$ long uniformly spaced fins; the heat transfer rate increased with decrease in fin width and spacing.
- Micro-channels, e.g. with width of $60-200 \mu \mathrm{m}$ and depths from 180 to $275 \mu \mathrm{m}$, etched in silicon plates [10] and with widths of $0.2-0.4 \mathrm{~mm}$ and depths from 0.100 to $0.400 \mathrm{~mm}$ [11]. Tang et al. [12] used interconnected micro-channels $(0.4-0.7 \mathrm{~mm}$ wide and $1.1 \mathrm{~mm}$ deep), formed in the copper porous matrix.

The objective of the present work was to compare heat transfer coefficients (HTCs) and heat fluxes of plain micro-fins and open micro-channels for flow boiling of water, ethanol and FC-72.

\section{Experimental investigations}

\subsection{Experimental apparatus}

The test station allows determination of the boiling curves $[3,13,14]$. The main section consisted of a cylindrical vessel made of glass filled with working fluid, i.e., ethanol, water, and FC-72, placed above the specimen. The specimen was soldered with a tin layer to a copper tubular rod. The thickness of the tin layer did not exceed $0.1 \mathrm{~mm}$. In the rod, a $1 \mathrm{~kW}$ electric heater was fitted and $\mathrm{K}$ type thermocouples were installed to determine the heat flux from the temperature gradient. The entire heating module was thermally insulated (Fig. 1). Experimental heat transfer experiments on the microfins and open micro-channels were performed under pool boiling conditions. Prior to the measurements, fluids were degassed in the test station. Measurement data were recorded using a Hydra 2635A data acquisition station (FLUKE) after temperature stabilization. The heat flux was increased until the boiling crisis was reached. The experiment was carried out at atmospheric pressure.

The estimated uncertainties were as follows [3]: at low heat flux $\left(2 \mathrm{~kW} / \mathrm{m}^{2}\right)$ : wall superheat at the micro-fin

\footnotetext{
* Corresponding author: tmprp@tu.kielce.pl
} 
and micro-channel base $\pm 0.2 \mathrm{~K}$, heat flux $\pm 35 \%$, heat transfer coefficient $\pm 40 \%$; at high heat flux (400 $\mathrm{kW} / \mathrm{m}^{2}$ ): wall superheat at the micro-fin and microchannel base $\pm 0.5 \mathrm{~K}$, heat flux $\pm 2.4 \%$, heat transfer coefficient $\pm 2.7 \%$.

The base heat transfer coefficient was expressed as:

$$
\alpha=\frac{q}{\Delta T_{\text {sat }}}
$$

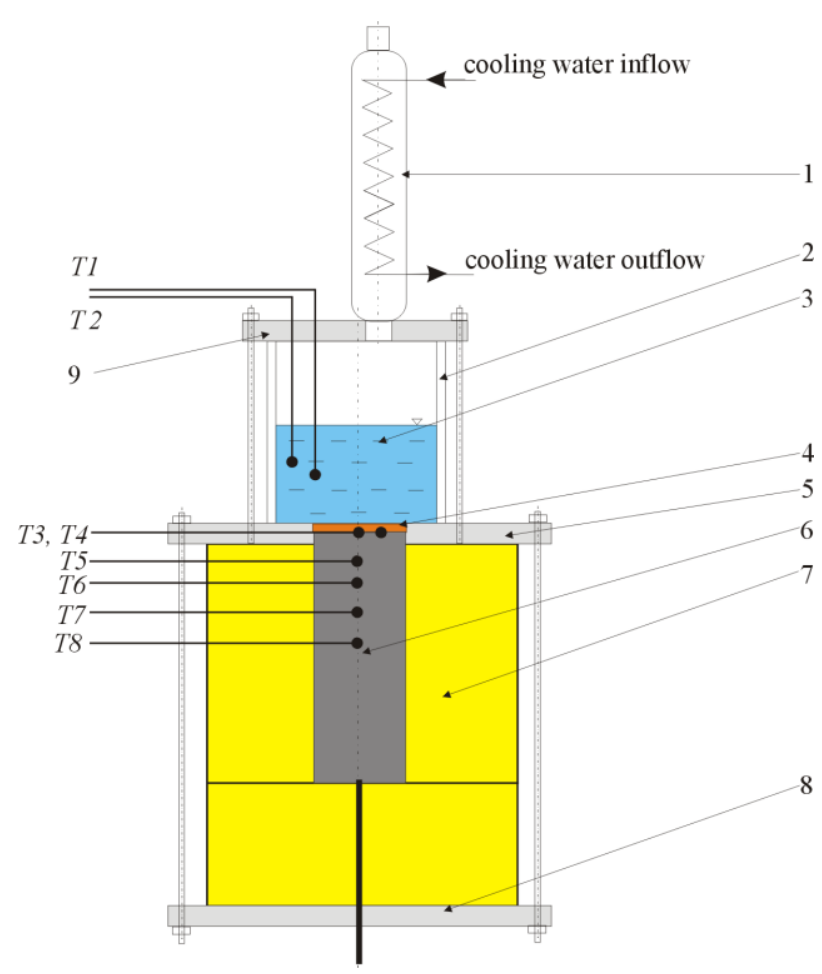

Fig. 1. Main section of pool boiling experimental station: $1-$ condenser, 2 - glass vessel, 3 - test fluid, 4 - test surface, 5 teflon lid, 6 - copper bar with cartridge heater, 7 - insulation, 8 - teflon base, 9 - top flange.

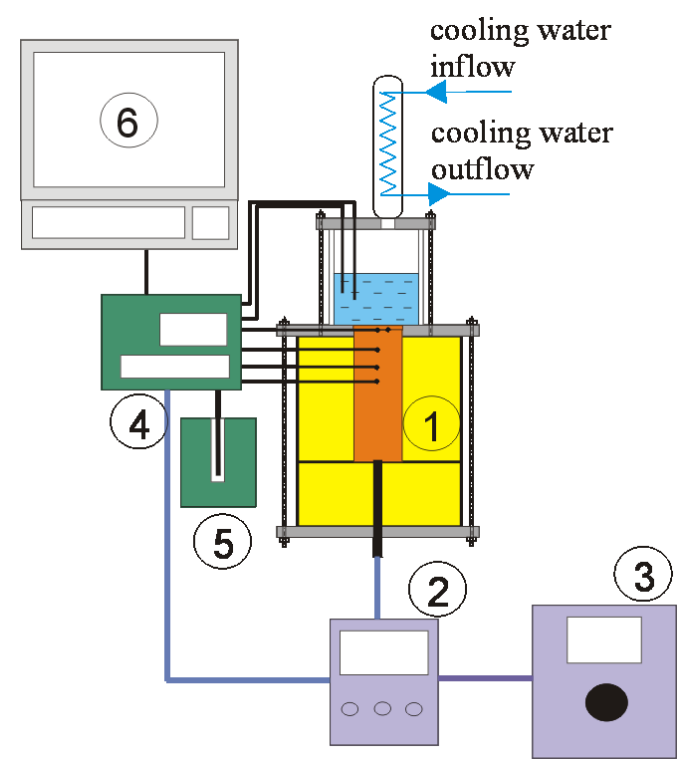

Fig. 2. Pool boiling measurement stand: 1 - main module, $2-$ wattmeter, 3 - autotransformer, 4 - data logger, 5 - dry-well calibrator, 6 - PC.

\subsection{Test surfaces}

The HTC values were compared on two types of structured surfaces: micro-fins and micro-channels. The test section consisted of a $32.5 \times 32.5 \mathrm{~mm}^{2}$ square copper specimen with a $26.8 \times 26.8 \mathrm{~mm}^{2}$ boiling region. The surfaces were produced with $\mathrm{CNC}$ milling cutters. The specimen surface had a mean roughness of $0.127 \mathrm{~m}$. Figure 3 shows photographs of the specimens with micro-fins and micro-channels, as well as typical dimensions in the pictorial diagrams. Table 1 compiles the surface codes and specifications. Surface extension coefficient was defined as:

$$
\varphi=\frac{A_{e x t}}{A_{b}}
$$

a)

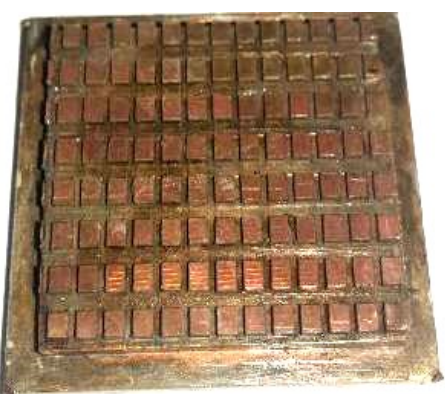

b)

c)
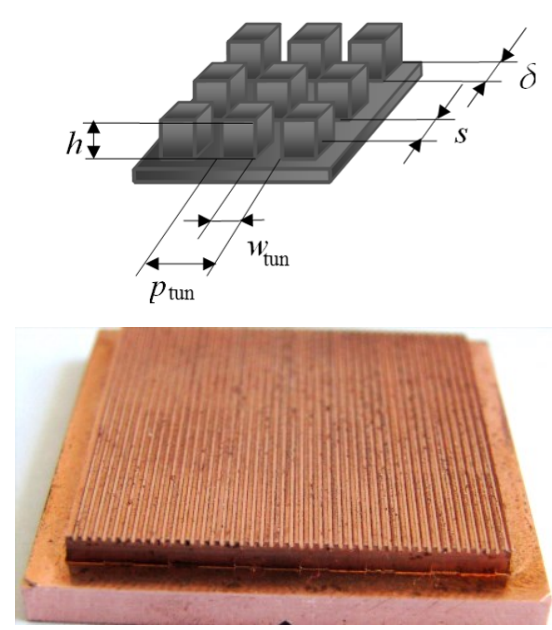

d)

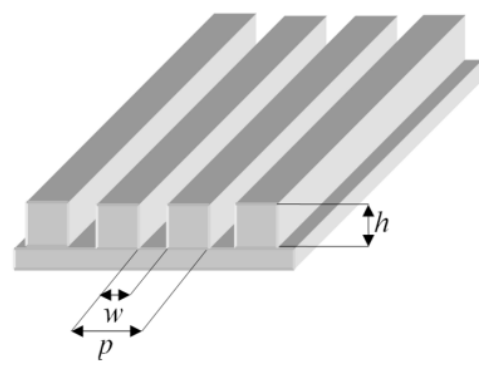

Fig. 3. a) View of the MF specimen, b) MF dimension symbols, c) view of the MC specimen, d) MC dimension symbols. 
Table 1. Surface codes and specifications.

\begin{tabular}{|c|c|c|c|c|c|c|}
\hline \multicolumn{2}{|c|}{ Specimen code } & $\begin{array}{c}w \\
\mathrm{~mm}\end{array}$ & & $\begin{array}{c}h \\
\mathrm{~mm}\end{array}$ & $\begin{array}{c}p \\
\mathrm{~mm}\end{array}$ & $\varphi$ \\
\hline \multicolumn{2}{|c|}{ MC-0.3-0.5-0.6 } & 0.3 & & 0.5 & 0.6 & 2,67 \\
\hline \multicolumn{2}{|c|}{ MC-0.3-0.4-0.6 } & 0.3 & & 0.4 & 0.6 & 2.33 \\
\hline \multicolumn{2}{|c|}{ MC-0.3-0.3-0.6 } & 0.3 & & 0.3 & 0.6 & 2.00 \\
\hline \multicolumn{2}{|c|}{ MC-0.3-0.2-0.6 } & 0.3 & & 0.2 & 0.6 & 1.67 \\
\hline Specimen code & $\begin{array}{l}w_{\text {tun }} \\
\mathrm{mm}\end{array}$ & $\begin{array}{c}h \\
\mathrm{~mm}\end{array}$ & $\begin{array}{c}\delta \\
\mathrm{mm}\end{array}$ & $\begin{array}{c}S \\
\mathrm{~mm}\end{array}$ & $\begin{array}{l}p_{\text {tun }} \\
\mathrm{mm}\end{array}$ & $\varphi$ \\
\hline MF-0.5-0.6 & 0.6 & 0.5 & 2 & 1.5 & 2 & 1.49 \\
\hline MF-0.5-1.0 & 1.0 & 0.5 & 2 & 1.5 & 2 & 1.43 \\
\hline MF-0.5-1.5 & 1.5 & 0.5 & 2 & 1.5 & 2 & 1.36 \\
\hline
\end{tabular}

\section{Results}

The Bo number, defined as $B o=w_{t u n} / L$ for micro-fins and $B o=w / L$ for micro-channel, was introduced to enable the comparison of the results for boiling of water, ethanol and FC-72. The capillary length is expressed by:

$$
L=\sqrt{\frac{\sigma}{g\left(\rho_{l}-\rho_{v}\right)}}
$$

The $L=2.5 \mathrm{~mm}$ for boiling water, $L=1.55 \mathrm{~mm}$ for boiling ethanol and $L=0.72 \mathrm{~mm}$ for boiling of FC-72. Capillary length is about 3.5 times greater for water than for FC-72 and 1.6 times greater for water than for ethanol. Table 2 compiles the calculated values of the $B o$ number for different specimens and fluids.

Table 2. Bond number values for MF and MC specimens

\begin{tabular}{cccc}
\hline Specimen code & \multicolumn{3}{c}{ Bo } \\
\cline { 2 - 4 } & water & ethanol & FC-72 \\
MF-0.5-0.6 & 0.24 & 0.38 & 0.83 \\
MF-0.5-1.0 & 0.40 & 0.65 & 1.39 \\
MF-0.5-1.5 & 0.60 & 0.97 & 2.10 \\
MC-0.3-0.5-0.6 & 0.12 & 0.19 & 0.42 \\
MC-0.3-0.4-0.6 & 0.12 & 0.19 & 0.42 \\
MC-0.3-0.3-0.6 & 0.12 & 0.19 & 0.42 \\
MC-0.3-0.2-0.6 & 0.12 & 0.19 & 0.42 \\
\hline
\end{tabular}

\section{Boiling of water}

Figures $4 \mathrm{a}$ and $4 \mathrm{~b}$ show HTC/heat flux and heat flux/ temperature superheat relationships at increasing heat flux on MF and MC surfaces for the boiling of water. Some of the data were taken from $[3,15,16]$.

Surfaces with micro-channels provide higher coefficients, as shown by the noticeable increase in heat transfer relative to surfaces with micro-fins. The coefficient depends on the micro-channel depth. The best results were shown by MC-0.3-0.3-0.6 specimen, where the maximum heat transfer coefficient $\alpha=64.4 \mathrm{~kW} / \mathrm{m}^{2} \mathrm{~K}$ at $\Delta T \approx 10.5 \mathrm{~K}$. Maximum HTCs of the MF surfaces were three times lower (max. 22.5 $\mathrm{kW} / \mathrm{m}^{2} \mathrm{~K}$ at about $320 \mathrm{~kW} / \mathrm{m}^{2}$ ).

\section{Boiling of ethanol}

Figure 5 shows ethanol boiling curves on the surfaces with micro-fins and micro-channels.
Slight variations in heat transfer intensities were observed between the MF and MC surfaces tested. Compared to the micro-fin surfaces, the only advantage of the micro-channel surfaces was the higher heat flux (up to $400 \mathrm{~kW} / \mathrm{m}^{2}$ ). The heat transfer coefficient was independent of the micro-channel depth. Of all the specimens tested, the best results were obtained for MC-0.3-0.3-0.6, where the heat transfer coefficient was $\alpha=20.3 \mathrm{~W} / \mathrm{m}^{2} \mathrm{~K}$ at $\Delta T \approx 15.7 \mathrm{~K}$. For medium flux values $\left(20-120 \mathrm{~kW} / \mathrm{m}^{2}\right)$, the MF-0.5-1.0 surface allowed obtaining the highest HTC.

\section{Boiling of FC-72}

The FC-72 boiling curves on the structured surfaces are shown in Fig. 6.

As with the boiling water, the highest HTC was obtained for micro-channels 0.3 and $0.5 \mathrm{~mm}$ deep about twice as high as those on the MF surface. The highest heat transfer enhancement was for MC-0.3-0.5-0.6, where the coefficient was $\alpha=9.8 \mathrm{~W} / \mathrm{m}^{2} \mathrm{~K}$ for superheat $\Delta T \approx 9.3 \mathrm{~K}$ and heat flux of $90 \mathrm{~kW} / \mathrm{m}^{2}$. The highest maximum heat flux, however, were provided by the surfaces with 0.3 and $0.4 \mathrm{~mm}$ deep micro-channels.

\section{Conclusions}

The experimental studies discussed in this paper lead to the following conclusions:

- Lower Bo number values obtained for $0.3 \mathrm{~mm}$ wide micro-channels and higher surface extension coefficients compared to micro-fin surfaces facilitate obtaining higher HTCs for MC surfaces.

- With boiling of water and FC-72, micro-channel surfaces have more than two times higher HTCs than those obtained by micro-fin surfaces.

- The effect of the structure type is the least during the boiling of ethanol - the differences between HTCs of MC and MF surfaces are negligible.

- The highest heat transfer coefficient $-63 \mathrm{~kW} / \mathrm{m}^{2} \mathrm{~K}$ at $q \approx 700 \mathrm{~kW} / \mathrm{m}^{2}$ for the boiling of water and 20 $\mathrm{kW} / \mathrm{m}^{2} \mathrm{~K}$ at $q \approx 390 \mathrm{~kW} / \mathrm{m}^{2}$ for the boiling of ethanol - was obtained for the surface with $0.3 \mathrm{~mm}$ deep open micro-channels.

- The performance of a $0.2 \mathrm{~mm}$ deep micro-channel is similar to that of $0.5 \mathrm{~mm}$ high micro-fins.

\section{Nomenclature}

A - area, $\mathrm{m}^{2}$,

Bo - Bond number,

$h \quad-$ micro-channel depth, $\mathrm{m}$,

HTC - heat transfer coefficient,

L - capillary length, $\mathrm{mm}$,

MC - micro-channel,

MF - micro-fin,

p - pitch, $\mathrm{m}$,

$q \quad-$ heat flux, $\mathrm{kW} / \mathrm{m}^{2}$,

w $\quad$ - width, $\mathrm{m}$. 
a)

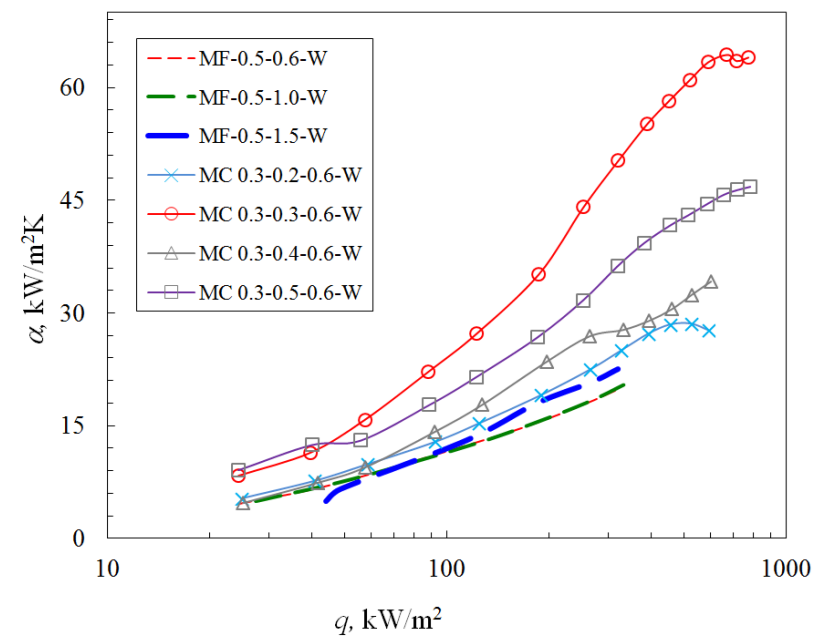

b)

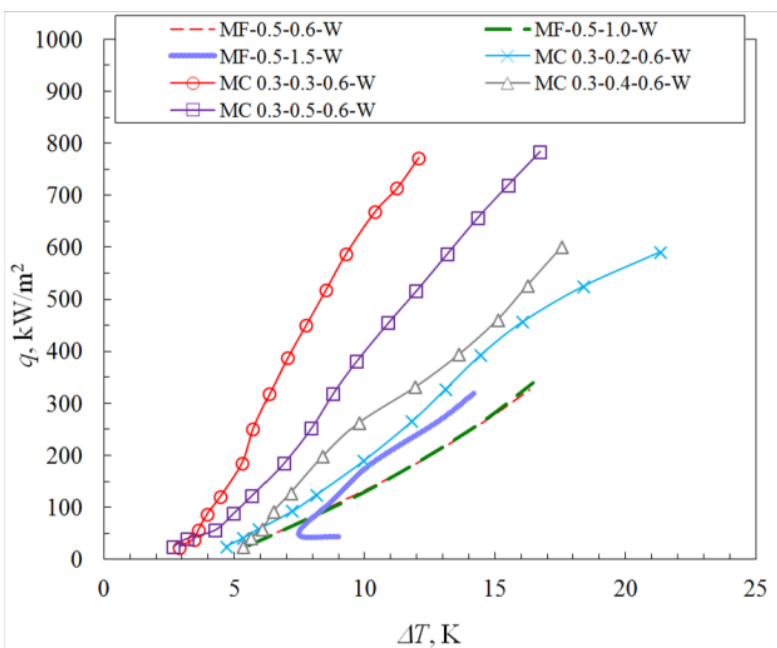

Fig. 4. Boiling curves for water, a) heat transfer coefficient vs. heat flux, b) heat flux vs. temperature difference.

a)

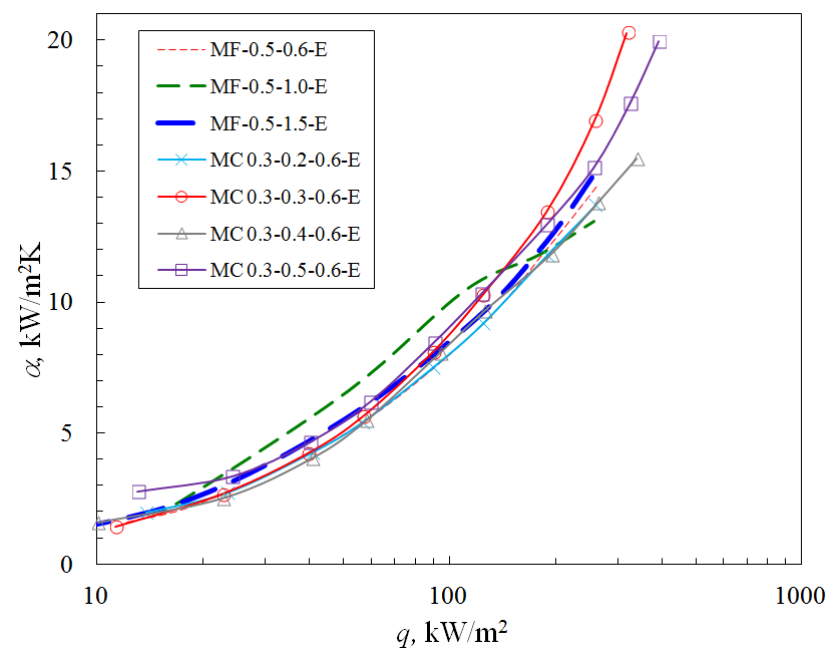

b)

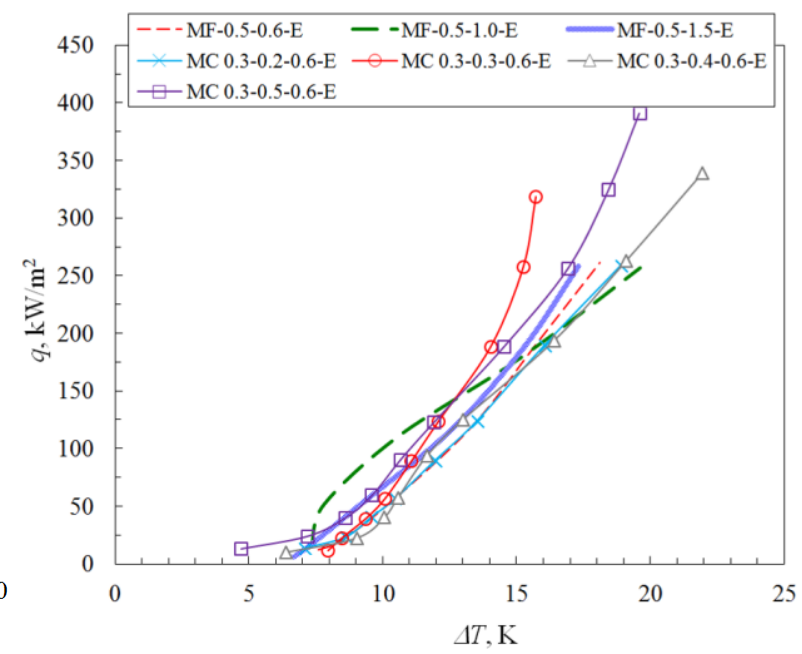

Fig. 5. Boiling curves for ethanol, a) heat transfer coefficient vs. heat flux, b) heat flux vs. temperature difference.

a)

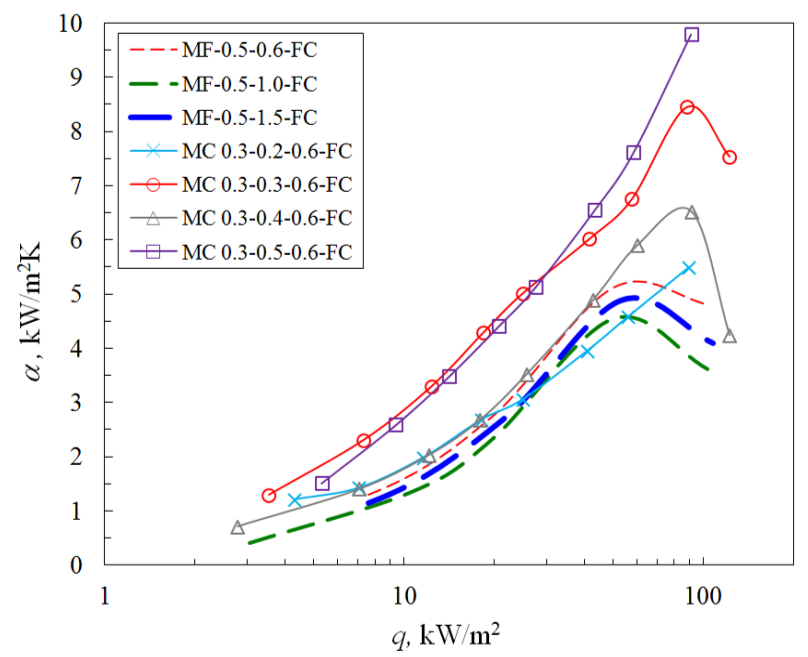

b)

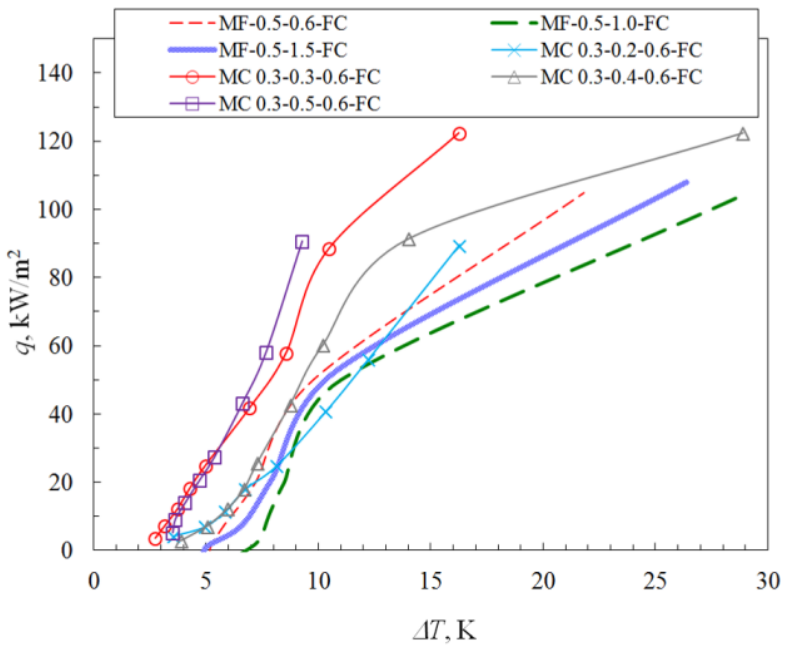

Fig. 6. Boiling curves for FC-72, a) heat transfer coefficient vs. heat flux, b) heat flux vs. temperature difference. 


\section{Greek symbols}

$\alpha \quad-$ heat transfer coefficient, $\mathrm{W} /\left(\mathrm{m}^{2} \mathrm{~K}\right)$,

$\Delta T$ - difference of temperature, $\mathrm{K}$,

$\varphi \quad-$ surface extension coefficient,

$\rho-$ density, $\mathrm{kg} / \mathrm{m}^{3}$,

$\sigma \quad-$ surface tension, $\mathrm{N} / \mathrm{m}$.

\section{Subscripts}

b - base,

ext - extended,

$l$ - liquid,

sat - saturation,

tun - tunnel,

$v$ - vapor.

\section{References}

1. A. Walunj, A. Sathyabhama, Appl. Therm. Eng. 128 (2018)

2. K. N. Rainey, S. M. You, J. Heat Transfer 122 (2000)

3. R. Pastuszko, Int. J. Therm. Sci. 49 (2010)

4. C. K. Yu, D. C. Lu, Int. J. Heat Mass Transfer 50 (2007)
5. M. A. Chan, C. R. Yap, K. C. Ng, J. Heat Transfer, 132 (2010)

6. H. Honda, H. Takamastu, J. J. Wei, J. Heat Transfer, 124 (2002)

7. J. J. Wei, H. Honda, Int. J. Heat Mass Transfer 46 (2003)

8. J. J. Wei, L. J. Guo, H. Honda, Heat Mass Transfer, 41 (2005)

9. G. Guglielmini, M. Misale, C. Schenone, Int. J. Therm. Sci. 41 (2002)

10. D. Cooke, S. G. Kandlikar, J. Heat Transfer 133 (2011)

11. D. Cooke, S. G. Kandlikar, Int. J. Heat Mass Transfer 55 (2012)

12. Y. Tang, J. Zeng, S. Zhang, C. Chen, J. Chen, Int. J. Heat and Mass Transfer 93 (2016)

13. R. Pastuszko, EPJ Web of Conferences 45, 01020 (2013)

14. M. Piasecka, Ann. Nucl. Energy 73 (2014)

15. R. Kaniowski, R. Pastuszko, L. Nowakowski, EPJ Web of Conferences 143, 02049 (2017)

16. R. Kaniowski, R. Pastuszko, EPJ Web of Conferences 143, 02050 (2017) 